\title{
Quantitative Radionuclide Studies of Bone
}

I

$\mathrm{n}$ the current issue of The Journal of Nuclear Medicine, Uchida et al. present results from a prospective study using ${ }^{18} \mathrm{~F}$-fluoride PET to assess the effects of bisphosphonate treatment on bone metabolism in patients with glucocorticoid-induced osteoporosis (1). By quantifying localized bone turnover in terms of ${ }^{18} \mathrm{~F}$-fluoride standardized uptake value (SUV) measured at the lumbar spine and femoral neck, the authors report a statistically significant decrease in SUV that parallels changes in biochemical markers of bone formation and bone resorption.

\section{See page 1808}

Quantitative measurements of bone remodeling have an important role in research studies examining the pathophysiology of metabolic bone diseases and the response of patients to treatment (2-6). The most accurate method is bone histomorphometry performed by taking a bone biopsy from the iliac crest $(7,8)$, and for the most detailed information the process of double tetracycline labeling is used (7). The limitation of bone biopsies is that they are a relatively invasive procedure that requires sedation of the patient. Also, the measurement site is restricted to the iliac crest, and when bone biopsy is used to assess response to treatment

Received May 20, 2009; revision accepted May 26, 2009.

For correspondence or reprints contact: Glen M. Blake, Osteoporosis Research Unit, 1st Floor, Tower Wing, Guy's Hospital, London, SE1 9RT, United Kingdom.

E-mail: glen.blake@kcl.ac.uk

COPYRIGHT ( 2009 by the Society of Nuclear

Medicine, Inc.

DOI: 10.2967/jnumed.109.063263 the patient is required to undergo serial biopsies.

In practice, the most widely used technique for studying bone remodeling is the measurement of biochemical markers of bone resorption and bone formation in serum or urine $(9,10)$. A variety of different markers has been studied, with bone resorption markers being the by-products of collagen breakdown and formation markers being chemicals released by osteoblasts during bone formation. Biochemical markers have the advantage of showing a rapid response in patients commencing treatment, and in postmenopausal women with osteoporosis treated with an antiresorptive agent such as a bisphosphonate, bone resorption markers decline rapidly to reach a new lower plateau within $4 \mathrm{wk}$ of the start of therapy (11). Consistent with the remodeling cycle, bone formation markers show no response at 4 wk but subsequently decline to reach a new plateau around 3 mo after the start of therapy. Rigorous quality control is required to achieve the best results when biochemical markers are used in research studies, with all the samples from a single study stored at $-70^{\circ} \mathrm{C}$ until they can be assayed together. A limitation of biochemical markers for monitoring individual patients is that any changes may be masked by the relatively large dayto-day variation in the measurements, including the presence of a significant diurnal rhythm for some markers $(12,13)$. Another major limitation is that measurements in serum or urine reflect processes occurring throughout the entire skeleton. Although constituting only $20 \%$ of the whole skeleton, trabecular bone is considerably more responsive to treatment than is cortical bone. It would be useful to have ways of selecting for measurement clinically important sites such as the spine and hip that have high trabecular bone content.

Bone densitometry using dual-energy x-ray absorptiometry is another method for monitoring changes in bone remodeling $(14,15)$. In patients starting treatment for osteoporosis, an increase in bone mineral density is observed at trabecular bone sites such as the spine and hip because of infilling of remodeling space (16). However, even at the most favorable measurement site, the lumbar spine, the changes are small and several years may be required before a statistically significant effect can be measured in an individual patient. Moreover, other factors, including the development of degenerative disease with aging, can complicate the interpretation of bone mineral density changes. In patients treated with a bisphosphonate, part of the bone mineral density increase is caused by the increased secondary mineralization of newly formed bone tissue associated with the longer remodeling cycle (17). For patients treated with strontium ranelate, exceptionally large bone mineral density changes are measured using dual-energy $\mathrm{x}$-ray absorptiometry, but these are caused by the replacement of some of the calcium atoms in bone by strontium, which attenuates $\mathrm{x}$-rays more strongly than does calcium (18).

Quantitative radionuclide studies of bone are of interest because they provide an alternative method for studying bone remodeling that avoids some of the limitations of the techniques described above (19). Studies using ${ }^{18}$ F-fluoride (20) or ${ }^{99 \mathrm{~m}} \mathrm{Tc}$-methylene diphosphonate (MDP) (21) reflect the combined effects of bone blood flow and osteoblastic activity on bone tracer kinetics (19). The advantage of an imaging technique such as PET is that quantitative studies of bone tracer kinetics can be performed directly at 
the spine or hip (22-34). The technique has been validated by comparison with bone histomorphometric indices, with significant correlations observed between regional skeletal kinetic parameters using ${ }^{18} \mathrm{~F}$-fluoride PET and the bone formation and mineral apposition rate $(23,27) .{ }^{18} \mathrm{~F}$ fluoride PET has been used to investigate regional bone metabolism in patients with metabolic bone disease $(23,24,28,31,33)$ and to evaluate therapies for these diseases $(30,33)$. In addition, important differences in remodeling activity between cortical and trabecula-rich sites can be investigated (26). ${ }^{18} \mathrm{~F}$-fluoride PET may also have an important role in the investigation of neovascularization after allogenic bone grafting, periprosthetic bone formation after joint replacement (35-37), and fracture healing (38).

Historically, quantitative radionuclide studies of bone have used one of two different approaches, the first being measurement of skeletal uptake defined as percentage of injected dose of tracer in a specified region of interest, and the second being measurement of plasma clearance from the relationship between the time-activity curve in the selected region of interest and the blood input curve. SUV is defined as tissue activity $(\mathrm{kBq} / \mathrm{mL}) \times$ body weight (kg)/injected activity $(\mathrm{MBq})$ and is equivalent to the measurement of tracer uptake per unit volume. Although SUV is frequently used to quantify PET studies, most ${ }^{18} \mathrm{~F}$-fluoride studies have used the alternative plasma clearance technique first described by Hawkins et al. (22). That method is technically more demanding than an SUV measurement, requiring a 60-min dynamic PET acquisition together with continuous blood sampling to accurately define the arterial input function. In addition, a compartmental modeling program is required for computation of the results.

A choice between measuring uptake or plasma clearance also exists for studies using the alternative tracer ${ }^{99 m}$ Tc-MDP. Perhaps the best-known technique for quantitative bone radio- nuclide studies is the $24-\mathrm{h}{ }^{99 \mathrm{~m}} \mathrm{Tc}-\mathrm{MDP}$ whole-body retention test first described by Fogelman et al. (39). Because whole-body counters are no longer widely available, several authors have described equivalent methods for measuring ${ }^{99 \mathrm{~m}} \mathrm{Tc}-\mathrm{MDP}$ retention based on whole-body $\gamma$-camera bone scanning (40-42). These techniques are all measurements of tracer uptake, like SUV. However, by combining serial $\gamma$-camera imaging with blood sampling, one can also measure ${ }^{99 \mathrm{~m}} \mathrm{Tc}-$ MDP plasma clearance both for the whole skeleton and for selected regions of interest $(43,44)$.

Although uptake is technically much simpler to measure than plasma clearance, it is important to ask whether the choice of a simpler method entails any loss of information. One advantage of the PET compartmental modeling approach is that several different tracer kinetic parameters are available for study, including bone blood flow and net clearance to the bone mineral compartment (22). In contrast, a disadvantage of bone uptake measurements is that the results may be influenced by uncontrolled aspects of tracer kinetics from outside the immediate region of interest under study. These include the patient's renal function and the presence of bone lesions in other areas of the skeleton. An uptake measurement can be compared to dividing up the cake at a birthday party. Because there is only a finite amount of cake to share, if the number of guests is larger than expected each will receive a smaller slice of cake. In a similar way, there is competition for bone tracer from the kidneys and from bone lesions in other parts of the skeleton that may vary substantially from patient to patient. The advantage of plasma clearance measurements is that such effects are allowed for through their effect on the plasma clearance curve. Thus, in a patient with poor renal function, the plasma concentration decreases more slowly with time, making more tracer available for uptake at the bone measurement site. Similarly, in a patient with widespread Paget's disease, there is more competition for tracer, and the plasma concentration decreases more quickly with time, leading to less tracer being available for uptake (45).

An important practical consideration when one is designing research studies is the precision of measurements (34). For studies in which individual patients serve as their own controls, the number of subjects required to achieve a statistically significant difference between the results of the baseline and follow-up measurements, assuming a $P$ value of 0.05 and a power of $90 \%$, is $21 \times$ (precision error/treatment effect) ${ }^{2}$. In this equation, the treatment effect is the average difference between the 2 measurements expressed either as percentage change from baseline or in the natural units of the measurement. The precision error is the root mean square precision measured in a group of subjects (34) and similarly can be expressed either as a percentage or in natural units. A technique that has a smaller figure for the ratio of precision error to treatment effect will be more cost-effective in research studies because fewer subjects will be required to achieve a statistically significant result. Studies show that precision errors of as low as $12 \%-14 \%$ can be achieved with ${ }^{18} \mathrm{~F}$ fluoride PET using both the SUV and plasma clearance techniques (34).

Finally, is there any advantage between ${ }^{18} \mathrm{~F}$-fluoride and ${ }^{99 \mathrm{~m} T c-M D P}$ as tracers for studying bone metabolism? Few studies have directly compared the 2 tracers, but results suggest that whole skeleton plasma clearance measured with ${ }^{18} \mathrm{~F}$-fluoride is around twice that measured with ${ }^{99 \mathrm{~m}} \mathrm{Tc}-\mathrm{MDP}$ (46), probably reflecting the lighter and more diffusible $\mathrm{F}^{-}$ion. A complication of the use of ${ }^{99 \mathrm{~m}} \mathrm{Tc}-\mathrm{MDP}$ is the significant and variable degree of protein binding, requiring ultrafiltration of plasma samples to derive the true input function (44), whereas ${ }^{18} \mathrm{~F}$ fluoride has the advantage of not binding to plasma proteins (47). However, other aspects of ${ }^{18} \mathrm{~F}$-fluoride kinetics may complicate their evaluation. Although free (e.g., non-proteinbound) ${ }^{99 \mathrm{~m} T c-M D P}$ is cleared by 
glomerular filtration, ${ }^{18} \mathrm{~F}$-fluoride has a variable renal clearance that is sensitive to urine flow rate and, therefore, the degree of hydration of the patient $(19,48,49)$, possibly affecting the interpretation of some types of study.

Quantitative radionuclide studies of bone turnover now have a wellestablished role in research studies that include investigations of the pathophysiology of metabolic bone diseases and studies of patients' response to pharmaceutical treatments and surgical interventions. At present, we can choose between ${ }^{99 \mathrm{~m}} \mathrm{Tc}-\mathrm{MDP}$ and ${ }^{18} \mathrm{~F}$ fluoride as possible tracers, and between straightforward approaches to scan quantification such as SUV or the more complicated plasma clearance techniques. There remains, however, the challenge of developing and validating simpler methods that may have wider clinical use. It is likely that much still remains to be learned in terms of developing the optimum technique.

\section{Glen M. Blake \\ Michelle L. Frost \\ Ignac Fogelman}

King's College London School of Medicine London, United Kingdom

\section{REFERENCES}

1. Uchida $K$, Nakajima $H$, Miyazaki $T$, et al. Effects of alendronate on bone metabolism in glucocorticoid-induced osteoporosis measured by ${ }^{18} \mathrm{~F}$-fluoride PET: a prospective study. $\mathrm{J} \mathrm{Nucl} \mathrm{Med.}$ 2009;50:1808-1814.

2. Reid IR, Brown JP, Burckhardt P, et al. Intravenous zoledronic acid in postmenopausal women with low bone density. N Engl J Med. 2002;346:653661.

3. Eastell R, Barton I, Hannon RA, et al. Relationship of early changes in bone resorption to the reduction in fracture risk with risedronate. $J$ Bone Miner Res. 2003;18:1051-1056.

4. Meunier PJ, Roux C, Seeman E, et al. The effects of strontium ranelate on the risk of vertebral fracture in women with postmenopausal osteoporosis. N Engl J Med. 2004;350:459-468.

5. Greenspan SL, Bone $\mathrm{HG}$, Ettinger $\mathrm{MD}$, et al. Effect of recombinant human parathyroid hormone (1-84) on vertebral fracture and bone mineral density in postmenopausal women with osteoporosis: a randomised trial. Ann Intern Med. 2007; 146:326-339.

6. Black DM, Delmas PD, Eastell R, et al. Onceyearly zoledronic acid for treatment of postmenopausal osteoporosis. N Engl J Med. 2007;356: 1809-1822.
7. Recker RR, Barger-Lux MJ. Bone biopsy and histomorphometry in clinical practice. In Favus MJ, ed. Primer on the Metabolic Bone Diseases and Disorders of Mineral Metabolism. 6th ed. Washington DC: American Society for Bone and Mineral Research; 2006:161-169.

8. Recker R, Lappe J, Davies KM, et al. Bone remodeling increases substantially in the years after menopause and remains increased in older osteoporosis patients. J Bone Miner Res. 2004; 19:1628-1633.

9. Camacho P, Kleerekoper M. Biochemical markers of bone turnover. In Favus MJ, ed. Primer on the Metabolic Bone Diseases and Disorders of Mineral Metabolism. 6th ed. Washington DC: American Society for Bone and Mineral Research; 2006:127-133.

10. Seibel MJ, Eastell R, Gundberg CM, et al. Biochemical markers of bone metabolism. In Bilezikian JP, Raisz LG, Rodan GA, eds. Principles of Bone Biology. San Diego CA: Academic Press; 2002:1543-1571.

11. Garnero P, Weichung JS, Gineyts E, et al. Comparison of new biochemical markers of bone turnover in late postmenopausal osteoporotic women in response to alendronate treatment. $J$ Clin Endocrinol Metab. 1994;79:1693-1700.

12. Beck-Jensen JE, Kollerup G, Sorensen HA, et al. A single measurement of biochemical markers of bone turnover has limited utility in the individual person. Scand J Clin Lab Invest. 1997; 57:351-359.

13. Looker AC, Bauer DC, Chesnut $\mathrm{CH}$, et al. Clinical use of biochemical markers of bone remodelling: current status and future directions. Osteoporos Int. 2000;11:467-480.

14. Blake GM, Fogelman I. Monitoring treatment for osteoporosis by using bone densitometry. Semin Nucl Med. 2001;31:212-222.

15. Blake GM, Fogelman I. The role of DXA bone density scans in the diagnosis and treatment of osteoporosis. Postgrad Med J. 2007;83:509-517.

16. McClung MR, San Martin J, Miller PD, et al. Opposite bone remodelling effects of teriparatide and alendronate in increasing bone mass. Arch Intern Med. 2005;165:1762-1768.

17. Boivin G, Meunier PJ. Effects of bisphosphonates on matrix mineralisation. J Musculoskelet Neuronal Interact. 2002;2:538-543.

18. Blake GM, Lewiecki EM, Kendler DL, et al. A review of strontium ranelate and its effect on DXA scans. J Clin Densitom. 2007;10:113-119.

19. Blake GM, Park-Holohan S-J, Cook GJR, et al. Quantitative studies of bone with the use of ${ }^{18} \mathrm{~F}$-fluoride and ${ }^{99 \mathrm{~m}} \mathrm{Tc}$-methylene diphosphonate. Semin Nucl Med. 2001;31:28-49.

20. Blau M, Ganatra R, Bender MA. ${ }^{18} \mathrm{~F}$-fluoride for bone imaging. Semin Nucl Med. 1972;2:31-37.

21. Subramanian G, McAfee JG, Blair RJ, et al. Technetium-99m-methylene diphosphonate: a superior agent for skeletal imaging-comparison with other technetium complexes. J Nucl Med. 1975; 16:744-755.

22. Hawkins RA, Choi Y, Huang S-C, et al. Evaluation of the skeletal kinetics of fluorine-18-fluoride ion with PET. J Nucl Med. 1992;33:633-642.

23. Messa C, Goodman WG, Hoh CK, et al. Bone metabolic activity measured with positron emission tomography and ${ }^{18} \mathrm{~F}$-fluoride ion in renal osteodystrophy: correlation with bone histomorphometry. J Clin Endocrinol Metab. 1993;77:949955.

24. Schiepers C, Nuyts J, Bormans G, et al. Fluoride kinetics of the axial skeleton measured in vivo with fluorine-19-fluoride PET. J Nucl Med. 1997;38: 1970-1976.

25. Schliephake H, Berding G, Knapp WH, Sewilam S. Monitoring of graft perfusion and osteoblast activity in revascularised fibula segments using ${ }^{18} \mathrm{~F}$-positron emission tomography. Int $\mathrm{J}$ Oral Maxillofac Surg. 1999;28:349-355.

26. Cook GJ, Lodge MA, Blake GM, Marsden PK, Fogelman I. Differences in skeletal kinetics between vertebral and humeral bone measured by ${ }^{18}$ F-fluoride positron emission tomography in postmenopausal women. $J$ Bone Miner Res. 2000;15:763-769.

27. Piert M, Zittel TT, Becker GA, et al. Assessment of porcine bone metabolism by dynamic ${ }^{18} \mathrm{~F}$ fluoride PET: correlation with bone histomorphometry. J Nucl Med. 2001;42:1091-1100.

28. Cook GJ, Blake GM, Marsden PK, Cronin B, Fogelman I. Quantification of skeletal kinetic indices in Paget's disease using dynamic ${ }^{18} \mathrm{~F}$ fluoride positron emission tomography. $J$ Bone Miner Res. 2002;17:854-859.

29. Piert M, Zittel TT, Jahn M, Stahlschmidt A, Becker GA, Machulla H-J. Increased sensitivity in detection of porcine high-turnover osteopenia after total gastrectomy by dynamic ${ }^{18} \mathrm{~F}$-fluoride ion PET and quantitative CT. J Nucl Med. 2003; 44:117-124.

30. Frost ML, Cook GJ, Blake GM, Marsden PK, Benatur NA, Fogelman I. A prospective study of risedronate on regional bone metabolism and blood flow at the lumbar spine measured by ${ }^{18} \mathrm{~F}-$ fluoride positron emission tomography. $J$ Bone Miner Res. 2003;18:2215-2222.

31. Frost ML, Cook GJ, Blake GM, Marsden PK, Fogelman I. Dissociation between global markers of bone formation and direct measurement of spinal bone formation in osteoporosis. J Bone Miner Res. 2004;19:1797-1804.

32. Brenner W, Vernon C, Muzi M, et al. Comparison of different quantitative approaches to ${ }^{18} \mathrm{~F}$-fluoride PET scans. J Nucl Med. 2004;45:1493-1500.

33. Installe J, Nzeusseu A, Bol A, Depresseux G, Devogelaer JP, Lonneux M. ${ }^{18} \mathrm{~F}$-fluoride PET for monitoring therapeutic response in Paget's disease of bone. J Nucl Med. 2005;46:16501658.

34. Frost ML, Blake GM, Park-Holohan S-J, et al. Long-term precision of ${ }^{18} \mathrm{~F}$-fluoride PET skeletal kinetic studies in the assessment of bone metabolism. J Nucl Med. 2008;49:700-707.

35. Piert M, Winter E, Becker GA, et al. Allogenic bone graft viability after hip revision arthroplasty assessed by dynamic ${ }^{18} \mathrm{~F}$ fluoride ion positron emission tomography. Eur J Nucl Med. 1999; 26:615-624.

36. Sörensen J, Ullmark G, Långström B, Nilsson O. Rapid bone and blood flow formation in impacted morselized allografts: positron emission tomography (PET) studies on allografts in 5 femoral component revisions of total hip arthroplasty. Acta Orthop Scand. 2003;74:633-643.

37. Temmerman OP, Raijmakers PG, Heyligers IC, et al. Bone metabolism after total hip revision surgery with impacted grafting: evaluation using $\mathrm{H}_{2}{ }^{15} \mathrm{O}$ and ${ }^{18} \mathrm{~F}$ fluoride PET-a pilot study. Mol Imaging Biol. 2008;10:288-293.

38. Hsu WK, Feeley BT, Krenek L, Stout DB, Chatziioannou AF, Lieberman JR. The use of ${ }^{18} \mathrm{~F}$-fluoride and ${ }^{18} \mathrm{~F}$-FDG PET scans to assess fracture healing in a rat femur model. Eur J Nucl Med Mol Imaging. 2007;34:1291-1301.

39. Fogelman I, Bessent RG, Turner JG, et al. The use of whole-body retention of Tc-99m 
disphosphonate in the diagnosis of metabolic bone disease. J Nucl Med. 1978;19:270-275.

40. D'Addabbo A, Rubini G, Mele M, et al. A new method of assessing Tc-99m-MDP bone uptake from a bone scan image: quantitative measurement of radioactivity in global skeletal region of interest. Nucl Med Commun. 1992;13:55-60.

41. Brenner W, Bohuslavizki KH, Sieweke N, et al. Quantification of diphosphonate uptake based on conventional bone scanning. Eur J Nucl Med. 1997;24:1284-1290.

42. Scillitani A, Dicembrino F, Chiodini I, et al. Global skeletal uptake of Tc-99m-methylene diphosphonate (GSU) in patients affected by endocrine diseases: comparison with biochemical markers of bone turnover. Osteoporos Int. 2002;13: 829-834.

43. Moore AEB, Blake GM, Fogelman I. Validation of a blood sampling method for the measurement of ${ }^{99 \mathrm{~m}} \mathrm{Tc}$-methylene diphosphonate $\left({ }^{99 \mathrm{~m}} \mathrm{Tc}\right.$ MDP) plasma clearance. J Nucl Med. 2006;47: 581-586.

44. Moore AEB, Blake GM, Fogelman I. Quantitative measurements of bone remodelling using Tc-99m methylene diphosphonate bone scans and blood sampling. J Nucl Med. 2008;49: 375-382.

45. Gnanasegaran G, Moore AE, Blake GM, Vijayanathan S, Clarke SE, Fogelman I. Atypical Paget's disease with quantitative assessment of tracer kinetics. Clin Nucl Med. 2007;32: 765-769.

46. Blake GM, Park-Holohan S-J, Fogelman I. Quantitative studies of bone in postmenopausal women using ${ }^{18} \mathrm{~F}$-fluoride and ${ }^{99 \mathrm{~m}} \mathrm{Tc}$-methylene diphosphonate. J Nucl Med. 2002;43:338-345.

47. Taves DR. Electrophoretic mobility of serum fluoride. Nature. 1968;220:582-583.

48. Park-Holohan S-J, Blake GM, Fogelman I. Quantitative studies of bone using ${ }^{18} \mathrm{~F}$-fluoride and ${ }^{99 \mathrm{~m}} \mathrm{Tc}$ methylene diphosphonate: evaluation of renal and whole blood kinetics. Nucl Med Commun. 2001;22:1037-1044.

49. Hosking DJ, Chamberlain MJ. Studies in man with ${ }^{18}$ F. Clin Sci. 1972;42:153-161. 